\title{
Detection of different adulteration from milk with non-destructive approach(Near infrared spectroscopy): A short review
}

\author{
Agnibha Das Majumdar, Amandeep Kaur, Pavas, Neha Munjal,Uma Kamboj* \\ Lovely Faculty of Science and Technology, School of Chemical Engineering \\ and Physical Sciences, Lovely Professional University, Punjab-144411 \\ Tanay Pramanik \\ Department of Basic Science and Humanities, University of Engineering and Management, \\ University Area, Action Area III, B/5, Newtown, Kolkata-700160*
}

\begin{abstract}
The present article is a review work about the role of near infrared spectroscopy to detect different adulterantsin the milk. Milk is a nutritive food and very useful and healthy drink for the child and senior citizens. It has various nutrition parameters. But, to increase the profit many adulterantsare added in the milk which are very harmful for human body. The adulterants can be detected using various chemical methods which are time consuming, hazardous and destructive in nature.Thus there is need of a nondestructive, green and rapid method to detect the adulteration. Near Infrared spectroscopy (NIRS) is one of the most useful and robust technique which needs no minimal sample preparation and is rapid, green, and non destructive in nature. The review covers the various nondestructive methods to detect various adulterants.
\end{abstract}

Keywords: Near infrared spectroscopy, Milk, Adulteration, Non-destructive method, chemometrics

\section{INTRODUCTION}

Milk is the most ideal class of food as it meets the all needs of nutrients of our body. Worldwide production of milk can be entirely derived from dairy animals like cows, buffaloes, sheep and camels. Less common species are yak, horses, reindeers and donkeys. Milk is consumed as a whole and various dairy products such as whole milk, milk, butter milk,yogurt,cheese,ice cream are its byproducts. From all the dairy products best source of calcium are cheese,yogurt and milk though all products are rich sources of energy. The major adulterantof milk is water i.e. $90 \%$. Thestudy investigated the major constituents of milk obtained from four different breeds of cows viz; Holstein Friesian (HF), White Fulani (WF), Red bororo $(\mathrm{RB})$ and a crossbreed $(\mathrm{HF}+\mathrm{WF})$ found in Sokoto metropolis. A crossbreed between RB and HF holds a possibility of better nutrient yield, as this local breed (RB) appears to be a better dairy cattle than WF $[1]$.

Milk is a perishable product so many Adulterants are added to increase the shelf life of milk. Common Adulterants are hydrogen per oxide $\mathrm{H}_{2} \mathrm{O}_{2}$, Starch, Urea, Detergents,Melamine, powdered milk,table sugar and buffalo milk in Cow milk. Near-infrared (NIR) technology is suitable for the qualitative and quantitative determination of food products due to its nondestructive nature. Various analytical methods used for detection of milk composition are destructive, expensive, time and requires expertise, hazardous chemicals and are off-line by nature[2].

Some adulterants and their tracing with destructive method:

\footnotetext{
*Corresponding author email:-amukam@gmail.com
}

1. Adulterant name: Hydrogen per oxide $\left(\mathrm{H}_{2} \mathrm{O}_{2}\right)$

Purpose of adulteration:To activate inherent use of lactoperoxidaze enzyme system. How to detect $\mathrm{H}_{2} \mathrm{O}_{2}$ experiment: Take about $5 \mathrm{ml}$ of milk in a test tube and add 5 drops of paraphenylenediamine to it and shake well.

\section{Adulterant name: Starch}

Purpose of adulteration: This reduces the amount of fat present in milk and rise the content of SNF(Solid Not Fat) in milk. How to detect Starch experiment ; Boil about $3 \mathrm{ml}$ of milk in a test tube and add $2-3$ drops of $1 \%$ Iodine solution to it after cooling.

3. Adulterant name: Urea Purpose of adulteration: To increase non-protein nitrogen content in milk. How to detect Urea experiment: Mix half of table spoon of milk and soybean powder together and shake well. Keep for $5 \mathrm{~min}$ and then for $30 \mathrm{sec}$ dip the litmus paper into it. Colour changes from red to blue.

4. Adulterant name: Detergent Purpose of adulteration: The substances caustic soda, sodium bicarbonate and sodium carbonate are added to prevent curdling. How to detect Detergent experiment:Take about $5 \mathrm{~mL}$ of milk and add $0.1 \mathrm{ml}$ of broom cresol to it, color changes.

5. Adulterant name: Melamine Purpose of adulteration: It is added into the milk to increase the nitrogen content and so the apparent protein count falsely in milk. How to detect Melamine experiment:It is detected by deamination test which works on the breaking of $\mathrm{C}-\mathrm{N}$ bonds in melamine to release Ammonia.

\section{American Journal of Physical Sciences and Applications US:ISSN 2644-0792}


6. Adulterant name: Table Sugar Purpose of adulteration:Sugar is added to increase the lactometer reading of milk, which was already diluted with water. How to detect Table sugar experiment:Take $5 \mathrm{ml}$ of $\mathrm{HCl}$ and $0.1 \mathrm{gm}$ of resorsinol. Add both of them to $10 \mathrm{ml}$ of milk. Place the test tube in a boiling water bath for $5 \mathrm{~min}$. Red colour indicates the presence of sugar [2].

\section{APPLICATION OF NEAR INFRARED SPECTROSCOPY FOR ADULTERATION DETERMINATION}

Milk products as well as different methods to detect adulterants pose serious health hazards leading to fetal diseases.Non Destructive method of NIR Spectroscopy is widely used for detecting adulterants in milk. Spectroscopy methods areused by scientists to identify pure substances and the elements in them. There are different types of spectroscopies, but the most common types used for chemical analysis include atomic spectroscopy, Ultraviolet and Visible spectroscopy, Infrared spectroscopy, Raman spectroscopy and nuclear magnetic resonance.Near infrared (NIR) spectroscopy is based on the absorption of electromagnetic (EM) radiation at wavelengths in the range 700 to $2,500 \mathrm{~nm}$. The light interacts with the sample and the detector measures its transmittance / absorbance. Near-infrared (NIR) spectroscopy and imaging are fast and nondestructive analytical techniques that provide chemical and physical information of virtually any matrix. In combination with multivariate data analysis these two methods open many interesting perspectives for both qualitative and quantitative analysis. Research work used NIR classification models to built by two non-linear supervised pattern recognition methods of improved support vector machine (I-SVM) and improved and simplified $\mathrm{K}$ nearest neighbors (IS-KNN). Uniform design theory was applied to optimize the parameters of SVM and thus the computation amount was reduced 90\%. Both two methods exhibit good adaptability in discriminating adulterated milks from raw cow milks. Further investigation showed that the correction ratio for discriminating milk samples increased with the increasing of adulteration solutions' level in the adulterated milk. The concentration of adulterants is an important factor of influencing milk discrimination results of the NIR pattern recognition models. The results demonstrated the usefulness of NIR spectra[3]. Cow milk adulteration involves the dilution of milk with a less-expensive component, such as water or whey. Near infrared spectroscopy (NIRS) was employed to detect the adulterations of milk, non-destructively. Two adulteration types of cow milk with water and whey were prepared, respectively. NIR spectra of milk adulterations and natural milk samples in the region of $1100-2500 \mathrm{~nm}$ were collected. The classification of milk adulterations and natural milk were conducted by using discriminant partial least squares (DPLS) and soft independent modeling of class analogy (SIMCA) methods. PLS calibration models for the determination of water and whey contents in milk adulteration were also developed, individually. Comparisons of the classification methods, wavelength regions and data pretreatments were investigated, and are reported in this study. This study showed that NIR spectroscopy can be used to detect water or whey adulterants and their contents in milk samples[4]. The adulteration of milk samples can be done qualitativelyon the basis of NIR spectra in a non- destructive, noninvasive and rapid method with no or little sample preparation as compared to the traditional destructive methods. All the adulterated milk samples can be classified on the basis oftheir amount of water added, only on the basis of the spectral data [5].

\section{CONCLUSION}

This work has a potential result on the analysis of the non-destructive evaluation of the different adulterants present in the milk sample. Different calibration modelhas been developed and successfully validated to detect the purpose. Model has proved the importance of the work and destructive approach can be replaced by the near infrared spectroscopy approach.
[1] Dandare, S. U., Ezeonwumelu, I. J., \& Abubakar, M. G. (2014). Comparative analysis of nutrient composition of milk from different breeds of cows. Scholars Research Library European Journal of Applied Engineering and Scientific Research, 3(2), 33-36.

[2] Kamboj, U., Kaushal, N., \& Jabeen, S. (2020, May). Near Infrared Spectroscopy as an efficient tool for the Qualitative and Quantitative Determination of Sugar Adulteration in Milk. In Journal of Physics: Conference Series (IOP Publishing),1531(1),012024.

[3] Zhang, L. G., Zhang, X., Ni, L. J., Xue, Z. B., Gu, X., \& Huang, S. X. (2014). Rapid identification of adulterated cow milk by non-linear pattern recognition methods based on near infrared spectroscopy. Food chemistry, 145, 342348.

[4] Kasemsumran, S., Thanapase, W., \& Kiatsoonthon, A. (2007). Feasibility of near-infrared spectroscopy to detect and to quantify adulterants in cow milk. Analytical Sciences, 23(7), 907-910.

[5] Kamboj, U., Kaushal, N., Mishra, S., \& Munjal, N. (2020). Application of Selective Near Infrared Spectroscopy for Qualitative and Quantitative Prediction of Water Adulteration in Milk. Materials Today: Proceedings, 24, 2449-2456. 